DOI: 10.20472/IAC.2018.001.027

\author{
ANITHITA YOMASARN \\ Suan Sunandha Rajabhat University, Thailand
}

SANSANEE JASUWAN

Suan Sunandha Rajabhat University, Thailand

\title{
GUIDELINES FOR THE ENHANCEMENT OF MATERIAL DISBURSEMENT SYSTEM FOR THE GRADUATE SCHOOL OF SUAN SUNANDHA RAJABHAT UNIVERSITY, THAILAND
}

\begin{abstract}
:
The primary objective of this study were to study problems of the disbursement management of the staff members of the Graduate School, Suan Sunandha Rajabhat University, Thailand and propose to guideline to develop an efficient material disbursement system. A quantitative research methodology was employed in this study. The research sample consisted of 18 staff members who worked in the Disbursement Section. The study was undertaken between September 2017- July 2018. A questionnaire was used as a data collection tool. The data were analyzed with descriptive statistics including percentage, mean, and standard deviation. The research findings showed that in terms of the problem, having too many steps in the procurement procedure was found to be the most found problem. This is because related staff members had to face with difficulties and undergo with many steps which were complex and involved many stakeholders. The proposed guideline for enhancing the efficiency of the material disbursement system was that some unnecessary steps in the procurement procedure must be cut short especially those involving the documents, the Disbursement Section should have a clear plan for the procurement and only necessary material should be procured. These actions could help the operation in this section faster. Moreover, new staff member in this section should gain a proper training.
\end{abstract}

\section{Keywords:}

Guidelines for the Enhancement, Management, Materials, Disbursement

JEL Classification: Y80 


\section{Background and Significance}

The material disbursement management is very significant and represents a key to success that enables the organization to achieve its vision and goals. Organizations, whether small or large, needs efficient and effective material disbursement management. As for the national level, the material disbursement management is also important. The government has set standards for it which is known as "Regulation of the Office of the Prime Minister on Procurement B.E.2535". The Higher Education Commission has realized the importance of the material disbursement management by providing a training on this regulation for the staff members of the universities so that they can work accurately and efficiently ( The Higher Education Commission, 2010).

The Graduate School of Suan Sunandha Rajabhat University is an organization that uses the Regulation of the Office of the Prime Minister on Procurement as a guideline to work on the material disbursement. At the present, staff members working on the material disbursement have faced many problems that affect their performance. With this reason, the researcher was interested to study on the guideline to enhance the efficiency of the material disbursement management of the Graduate School with the aim to improve the working process and to solve the problems. The researcher realized that the task of material disbursement could affect the performance of other works of the organization (Kanokrat Klaitongkum, 1998). The staff members in charge of this task needs to have proper and accurate knowledge of related regulations and laws because they did something wrong, they might be punished according to the law. The situation shows the point to develop in order to achieve the vision and strategy. The problem is that management is an important task in quality development. This is because the administration involves all activities in the development. Improve to achieve the goal by quality management (Sajeewan Darbavasu, 2012).

The material disbursement management involves working with many steps that are linked with each other. These include the procurement, the determination of the plan, the determination of materials specifications, checking the materials, control of the materials, and amortization of the deteriorate materials. The researcher would like to examine the problems of the material disbursement management faced by the staff members and propose the guidelines for enhancing the efficiency of this task.

\section{Research Objectives}

This study primarily aimed to:

1) Study problems of the disbursement management of the staff members of the Graduate School, Suan Sunandha Rajabhat University, Thailand; and

2) Propose to guideline to develop an efficient material disbursement system. 


\section{Scope of the Research}

Scope of the population

The population of this research were the staff members who worked in the Disbursement Section of the Graduate School, Suan Sunandha Rajabhat University, Thailand.

Scope of variables to be studied

Variables of this study consisted of two groups:

1) Independent variables were the demographic factors of the staff members including gender, age, and educational level;

2) Dependent variables were the performance of the staff members of the disbursement management of the Graduate School, Suan Sunandha Rajabhat University which could be divided into three main aspects:

2.1) The procurement for materials and office supplies

2.2) The control of materials and office supplies

2.3) The amortization of materials and office supplies

\section{Research Methodology}

As this research aimed to examine the relationship between the staff members' demographic profile and their performance in terms of the procurement for materials and office supplies, the control of materials and office supplies, and the amortization of materials and office supplies, it employed a quantitative research methodology.

\section{Population and sample}

The population of the research were the staff member in the disbursement management of the Graduate School, Suan Sunandha Rajabhat University. The total number at the time of conducting this study was 20 .

All of the population were selected but two staff members were not convenient to join the study. As a result, 18 staff members were selected.

\section{Data collection method}

This study used a questionnaire to collect the data. This questionnaire was developed by the researcher. It was a close-ended questionnaire consisting of four main parts. It was tested for its content validity and reliability before using in the main study. The researcher collected the data by herself. The data collection was conducted for one month. 


\section{Data analysis}

The collected data were analyzed with descriptive statistics including frequency, percentage, and standard deviation.

\section{Research Results}

The data analysis showed that the staff members found that the problems of the disbursement management of the Graduate School in general were at a moderate level. When considering each aspect of the problems, it was found that the problems related to the procurement of the materials and office supplies were the most found. In the view of the staff members, the procurement procedures involved too many steps. The staff members had to face with difficulties and undergo with many steps which were complex and involved many computer programs and stakeholders. Therefore, it often caused confusion and delay in working. This was especially a case of the procurement of computers which appeared to involve the determination of specifications of the computer and many steps. It happened many times this task caused problems for the work in the Graduate School.

The second problems that was found most were those involved with the control of the materials and office supplies. These included the movement of the materials and office supplies from one place to the another place without notifying responsible peoples or related staff members. Therefore, this caused missing of some materials/office supplies. Moreover, the staff members also faced with the problem of insufficient place to store the materials/office supplies as well as lacking of specific staff member who could maintain and manage these materials/office supplies.

The third problems involved problems related to the amortization of the materials/office supplies. In the view of the staff members, these problems included, sorted in a descending order, insufficient places to store materials/office supplies which were found to be deteriorated, working time of the staff members who were in charge of checking the conditions of materials/office supplies which was not consistent with other staff members, and lack of attention to work.

The proposed guidelines for enhancing the efficiency of the material disbursement system were as follows. In terms of the procurement of the materials and office supplies, some unnecessary steps in the procurement procedure must be cut short especially those involving the documents, and computer programs. Moreover, there should be a training the new staff members.

In terms of the control of the materials/office supplies, the Disbursement Section should have a clear plan for the procurement and only necessary material should be procured. These actions could help the operation in this section faster. The guidelines 
for borrowing and returning the materials should be set, and a book for recording the date and time for borrowing and returning the materials should be provided, clear rules and regulations related to the movement of the materials should be set, staff members should be changed frequently, and barcode system for the materials should be set.

As for the amortization of the materials, checking system for deteriorate materials should be set, the amortization of the materials should be conducted more than once in a year, and deteriorate materials should be stored in one place.

\section{References}

Intharaphuk, P. (2003). A study of problems and ways to solve the difficulties encountered by the administrators and staff alike within the supply divisions of Rajabhat Institutes.

Phitsanulok: Pibulsongkram Rajabhat University.

Klaitongkum, K. (1998). Problems and guided solution of material supplied administration in Burapha University. Chonburi: Burapha University.

Office of the Higher Education Commission. (2010). Manual for the internal quality assurance for higher education institution. Bangkok: Parbpim.

Darbavasu, S. (2012). Development of Academic Administration Process of the Basic Education Schools based on the Quality Management Concept. Research and Development Institute Suan Sunandha Rajabhat University. 